\title{
The benefit of experience: patient perception of asthma self-management
}

Many national and international asthma guidelines contain strong evidence-based recommendations for the provision of written asthma action plans to patients with asthma. In an editorial in this journal in 2004, ${ }^{1}$ Gibson highlighted the mismatch between the available evidence for the efficacy of written action plans ${ }^{2}$ and for their components, ${ }^{3}$ and the proportion of patients who had been given a written action plan. Since then, there has been further evidence of the decline in patient ownership of action plans. ${ }^{4}$ Insight into reasons behind the lack of adoption of asthma action plans has come from several sources. Goeman and colleagues found that general practitioners (GPs) place a low priority on action plans, particularly those plans that encourage self-management. ${ }^{5}$ Jones and colleagues highlighted the negative effect - on clinicians' use of action plans - of confusion about what the instructions should be, and concerns about whether self-management was an appropriate strategy. ${ }^{6}$

It has been known for some time that the attributes of guidelines themselves affect the likelihood of their uptake, with vague and nonspecific guidelines less likely to be adopted. ${ }^{7}$ The lack of clearly-defined protocols for action plans is a significant disincentive for their use. ${ }^{8}$ This immediately highlights a current problem with the specific content of asthma action plans, because of recent evidence about some action plan components which were originally considered to be 'standard'. The action plans which were included in the original Cochrane review used a wide range of trigger points and interventions, ${ }^{3}$ but most included an instruction to patients to double the dosage of their inhaled corticosteroid (ICS) treatment at the start of an asthma exacerbation, and to initiate a course of oral corticosteroids for more severe episodes. However, several recent placebo-controlled clinical trials have shown that doubling of ICS dose is not effective in the management of asthma exacerbations. ${ }^{9-12}$ The removal of this option leaves a conspicuous gap in the current options for construction of an action plan. Oral corticosteroids are cheap and effective in the treatment of severe exacerbations. However, further information is needed about the extent to which patients, with their known reluctance to use corticosteroid medications, ${ }^{13,14}$ would accept an action plan which moved straight from short-acting $B_{2}$-agonist to oral corticosteroids. As such plans would result in increased use of oral corticosteroids in the community, more data are also needed about the potential for overuse of oral corticosteroids and for cumulative side-effects.

Although doubling of ICS dose is now known to be ineffective, several studies have provided evidence for the efficacy of higher-dose ICS as an intermediate step in the management of exacerbations. ${ }^{15}$ A similar approach was also used in several open-label studies of so-called Adjustable Maintenance Dosing using Symbicort ${ }^{\oplus}$ (combination inhaled corticosteroid - budesonide - and rapidonset, long-acting $\beta_{2}$-agonist - formoterol). For example, in the study by Ind and colleagues, ${ }^{16}$ patients were reduced to a low maintenance dose of Symbicort ${ }^{\circledast}$ and were instructed to increase the dose to four puffs twice daily for up to 14 days for specified changes in symptoms (night waking on two consecutive nights, or reliever use $\geq 3$ times/day); this treatment was compared with a higher fixed dose of Symbicort ${ }^{\oplus}$. Although the 
concept of Adjustable Maintenance Dosing was subsequently abandoned by the sponsor company in favour of a more flexible dosing regimen, ${ }^{17}$ it provides a useful model for the systematic use of what was essentially a written asthma action plan. The clinical outcomes of the study showed that, with the use of a written action plan, patients could be managed on a lower maintenance dosage of Symbicort ${ }^{\oplus} .^{16}$

In this issue of the Primary Care Respiratory Journal, the paper by Haughney et al. ${ }^{18}$ touches on an issue relevant to action plans - the reporting of the validation of a modified Patient Enablement Instrument (PEI) at the end of the study by Ind and colleagues. ${ }^{16}$ These results provide an interesting insight into the potential effect of written action plans on patient attitudes. Enablement refers to a concept describing a patient's ability to cope with their disease and to have greater responsibility for their own care. Similar concepts have been described for asthma in terms of autonomy, ${ }^{19}$ participatory decision-making style,${ }^{20}$ and locus of control. ${ }^{21}$ The PEI used in the Haughney study ${ }^{18}-$ modified specifically for asthma - asked patients about the impact of their recent asthma treatment regimen on several features of selfmanagement efficacy. The authors report that patients receiving the adjustable maintenance treatment regimen had significantly higher PEI scores than patients receiving a higher fixed dose of Symbicort ${ }^{\oplus, 18}$ even though clinical outcomes in the two groups were similar. ${ }^{16}$ This suggests that the first-hand experience of using a formal written action plan within the structured environment of a clinical trial may have led to patients feeling better able to cope with their asthma (in the future) than patients for whom worsening asthma had been handled only in the conventional fashion by contact with the study investigator. For the study as a whole, about $80 \%$ of participants in the adjustable maintenance dosing arm reduced their Symbicort ${ }^{\oplus}$ dose below the starting level, and almost $30 \%$ increased their dose to 8 inhalations/day at least once during the treatment period. ${ }^{16}$

A similar action plan was studied in a recent Canadian study. ${ }^{22}$ Patients attending a respiratory physician were asked to evaluate three action plan templates. Two were "traditional" action plan templates on which the physician was to mark in the criteria for an increase in dose plus the actual dose adjustment, and the third was a simplified action plan which specified a quadrupling of inhaled corticosteroid dose for 14 days when asthma symptoms were increased for two days. To the authors' surprise, participants preferred the two traditional action plan templates over the simplified plan, although it was not clear whether this was because they preferred a more personalised plan, or that they equated complexity with efficacy, or that they disliked the concept of a quadrupling of inhaled corticosteroid dose. However, in contrast to the study by Haughney and colleagues, these patients were only required to comment on the action plan template and did not have the opportunity to use it themselves. Nevertheless, this study indicates the complexity involved in the design and testing of action plans.

For patients using combination ICS/long-acting $\beta_{2}$-agonist therapy, further developments have been occurring in the management of worsening asthma. For patients using a budesonide/formoterol combination, there are several very promising studies showing reduced exacerbations when the medication is used both for maintenance therapy and as-needed for symptom relief. ${ }^{17}$ The same approach is not appropriate for patients using a fluticasone/salmeterol combination (because of the slower onset of action of the salmeterol relative to formoterol), but it is possible that patients are already effectively adjusting their dose up and down to some extent according to their current status. ${ }^{14}$ For patients using a fluticasone/salmeterol combination inhaler, the addition of a high-dose fluticasone inhaler may be an intermediate step before use of oral corticosteroids, ${ }^{15}$ but the effectiveness and patient acceptability of this approach need to be evaluated formally.

Given the complexity of current therapeutic options for maintenance management of asthma, the needs of clinicians for simplicity in guidelines, and the desire of patients for individualised management, it is important that rapid progress should be made in developing and validating action plans for each of the common forms of asthma treatment. Clinicians need practical evidence-based advice about how to select and construct the most effective and appropriate action plan for all of their patients.

\section{References}

1. Gibson PG. Asthma action plans: use it or lose it. Prim Care Resp J 2004;13:17-18. doi:10.1016/j.pcrj.2003.12.001.

2. Gibson PG, Powell H, Coughlan J, et al. Self-management education and regular practitioner review for adults with asthma (Cochrane review). In. The Cochrane Library, Issue 1: Oxford: Update Software; 2003.

3. Gibson PG, Powell H. Written action plans for asthma: an evidence-based review of the key components. Thorax 2004;59:94-9.

4. Wilson DH, Adams RJ, Tucker G, Appleton S, Taylor AW, 
Ruffin RE. Trends in asthma prevalence and population changes in South Australia 1990-2003. Med J Aust 2006; 184:226-9.

5. Goeman DP, Hogan CD, Aroni RA, et al. Barriers to delivering asthma care: a qualitative study of general practitioners. Med J Aust 2005; 183:457-60.

6. Jones A, Pill R, Adams S. Qualitative study of views of health professionals and patients on guided self management plans for asthma. BMJ 2000;321:1507-10.

7. Grol R, Dalhuijsen J, Thomas S, Veld Cit, Rutten G, Mokkink $\mathrm{H}$. Attributes of clinical guidelines that influence use of guidelines in general practice: observational study. BMJ 1998;317:858-61.

8. Thoonen BP, Jones KP, van Rooij HA, et al. Self-treatment of asthma: possibilities and perspectives from the practitioner's point of view. Fam Pract 1999;16:117-22.

9. Garrett J, Williams S, Wong C, Holdaway D. Treatment of acute asthmatic exacerbations with an increased dose of inhaled steroid. Arch Dis Child 1998;79:12-17.

10. Harrison TW, Oborne J, Newton S, Tattersfield AE. Doubling the dose of inhaled corticosteroid to prevent asthma exacerbations: randomised controlled trial. Lancet 2004;363:271-5.

11. FitzGerald JM, Becker A, Sears MR, Mink S, Chung K, Lee J, Canadian Asthma Exacerbation Study G. Doubling the dose of budesonide versus maintenance treatment in asthma exacerbations. Thorax 2004;59:550-6.

12. Rice-McDonald G, Bowler S, Staines G, Mitchell C. Doubling daily inhaled corticosteroid dose is ineffective in mild to moderately severe attacks of asthma in adults. Intern Med J 2005; 35:693-8.

13. Boulet LP. Perception of the role and potential side effects of inhaled corticosteroids among asthmatic patients. Chest 1998;113:587-92.

14. Partridge MR, van der Molen T, Myrseth SE, Busse WW. Attitudes and actions of asthma patients on regular maintenance therapy: the INSPIRE study. BMC Pulmonary Medicine 2006;6:13.

15. Reddel HK, Barnes DJ. A review of pharmacological strategies for self-management of asthma exacerbations.
Eur Respir J 2006;28:182-99.

16. Ind PW, Haughney J, Price D, Rosen JP, Kennelly J. Adjustable and fixed dosing with budesonide/ formoterol via a single inhaler in asthma patients: the ASSURE study. Respir Med 2004;98:464-75.

17. Gibson PG. Teaching old drugs new tricks: asthma therapy adjusted by patient perception or noninvasive markers. Eur Respir J 2005;25:397-9.

18. Haughney J, Cotton P, Rosen J-P, Morrison K, Price D. The use of a modification of the Patient Enablement Instrument in asthma. Prim Care Resp J 2007;16(2):89-92. doi:10.3132/pcrj.2007.00014.

19. Gibson PG, Talbot PI, Toneguzzi RC. Self-management, autonomy and quality of life in asthma. Chest 1995; 107:1003-08.

20. Adams RJ, Appleton S, Wilson DH, Ruffin RE. Participatory decision making, asthma action plans, and use of asthma medication: a population survey. J Asthma 2005;42:673-8.

21. Nouwen A, Freeston MH, Labbe R, Boulet LP. Psychological factors associated with emergency room visits among asthmatic patients. Behav Modif 1999;23:217-33.

22. Beauchesne MF, Levert V, El Tawil M, Labrecque M, Blais L. Action plans in asthma. Can Respir J 2006;13:306-10.

Helen K Reddel*

Research Leader,

Woolcock Institute of Medical Research, University of Sydney, Australia

*Corresponding author.

PO Box M77, Missenden Rd, Camperdown, NSW 2050, Australia

Tel: +61 29515 7026; fax: +61295505865 E-mail address: hkr@med.usyd.edu.au

10th March 2007

Available online at http://www.thepcrj.org 